\title{
High-risk Factors of Respiratory Distress Syndrome in Term Neonates: A Retrospective Case-control Study
}

\author{
Jing Liu ${ }^{1}, \mathrm{Na}$ Yang ${ }^{1,2}$, Ying Liu ${ }^{1}$ \\ ${ }^{1}$ Department of Neonatology, NICU, Bayi Children's Hospital Affiliated to Beijing Military General Hospital, Beijing, China \\ ${ }^{2}$ Department of Neonatology, Maternal and Child Health Care Hospital of Hefei, Hefei City, China
}

Background: Respiratory distress syndrome (RDS) is a common critical disease in term neonates, but reasons for the occurrence of RDS remains unclear.

Aims: This study aimed to investigate the cause of RDS in full-term neonates by a retrospective case-control study.

Study Design: Case-control study.

Methods: Among the patients admitted to Bayi Children's Hospital between January 2008 and December 2010, a total of 205 full-term neonates with RDS were assigned to the study group, and 410 full-term neonates without RDS were assigned to the control group. Clinical information, including the presence or absence of premature rupture of membranes (PROM), gender of the neonates, mode of delivery, birth weight, and any conditions suffered by the neonates were recorded.

Results: The results of logistic regression analysis showed that the following causes were closely correlated with term neonatal RDS: selective cesarean section (OR: 8.737; 95\% CI: 5.232-14.588), severe birth asphyxia (OR: 6.988; 95\% CI: 2.990-16.333), small gestational age (OR: 6.222; 95\% CI: 2.001-8.993), maternal-fetal infection (OR: 5.337; 95\% CI: 1.999-8.233), PROM (OR: 3.380; 95\% CI: $1.986-$ 5.754), male sex (OR: 2.641; 95\% CI: 1.721-4.053), gestational glucose intolerance or diabetes (OR: 2.415; 95\% CI:1.721-4.053), and low birth weight (OR: 2.323 ; 95\% CI: 1.329-4.060).

Conclusion: Several high-risk factors, such as selective cesarean section, severe birth asphyxia, maternal-fetal infection, PROM, and male sex are closely correlated with full-term neonatal RDS. These could provide a significant reference for the diagnosis and treatment of term neonatal RDS.

(Balkan Med J 2014;31:64-68).

Key Words: Full-term, high-risk factors, neonate, respiratory distress syndrome
Respiratory distress syndrome (RDS) is one of the most common causes of neonatal respiratory failure and neonatal death. The underlying pathogenesis of RDS involves developmental immaturity of the lungs, leading to inadequate pulmonary surfactant (PS) production. It was previously believed that RDS mainly occurs in premature infants (1); however, with the application of antenatal corticosteroids and delivery room PS, typical and severe RDS in premature infants is now rarely diagnosed. Greater awareness of RDS has led to a more frequent diagnosis in term neonates (2-5). However, the reasons for the occurrence of RDS in term neonates are different from those in premature infants, and remain unclear. This study aimed to investigate the cause of RDS in full-term neonates by a retrospective case-control study, and thus provide a useful reference for its diagnosis and treatment.

\section{MATERIAL AND METHODS}

This investigation was approved by the ethics committee of the Beijing Military General Hospital. In this retrospective case-control study, the proportion of the case group (RDS patients) and control group (RDS-free patients) was 1:2. The following information was recorded: mode of delivery, birth asphyxia, premature rupture of membranes (PROM), maternal age at pregnancy, pregnancy hypertension disease, gestational glucose intolerance or diabetes, sex, birth weight, a cord around the neck with compression, oligohydramnios, meconium staining of amniotic fluid, severe fetal distress, and placental abruption.

From January 2008 to December 2010, a total of 205 full-term newborns with RDS who were admitted to the Department of Neonatology \& Neonatal Intensive Care Unit (NICU) (the largest NICU in the world with 350 beds; there are about 8,000 newborn infants admitted to this NICU within one year) at Bayi Children's Hospital, affiliated with the Beijing Military General Hospital of the Beijing Military Command, were assigned to this study. The diagnosis of term neonatal RDS met the following criteria (2-5): (1) full-term neonates (gestational age $\geq 37$ weeks); (2) acute onset; (3) an acute, explicit perinatal triggering insult, such as severe perinatal acquired infection, severe birth asphyxia, meconium aspiration syndrome, or delivery by selective cesarean section; (4) representative clinical manifestations, including progressive respiratory distress occurring shortly after birth, tachypnea, expiratory grunting, nasal flaring, 
TABLE 1. The analysis of risk factors in two groups ( $\mathrm{n}, \%)$

\begin{tabular}{|c|c|c|c|c|}
\hline Factors & Case group (205) & Control group (410) & $\chi^{2}$ & p-value \\
\hline Pregnancy age & & & 1.529 & 0.216 \\
\hline$\geq 35$ ys & $20(9.8 \%)$ & $28(6.8 \%)$ & & \\
\hline$<35$ ys & $185(90.2 \%)$ & $382(93.2 \%)$ & & \\
\hline Mode of delivery & & & 14.508 & $<0.001$ \\
\hline SCS & $71(34.6 \%)$ & $84(20.5 \%)$ & & \\
\hline Vaginal delivery+Non-SCS & $134(65.4 \%)$ & $326(79.5 \%)$ & & \\
\hline Pregnancy hypertension disease & & & 5.645 & 0.017 \\
\hline with & $22(10.7 \%)$ & $15(3.8 \%)$ & & \\
\hline without & $183(89.3 \%)$ & $395(96.2 \%)$ & & \\
\hline Abnormal glucose tolerance or diabetes & & & 5.047 & 0.025 \\
\hline with & $20(7.3 \%)$ & $20(5.0 \%)$ & & \\
\hline without & $185(92.7 \%)$ & $390(95.0 \%)$ & & \\
\hline Gender & & & 24.860 & $<0.001$ \\
\hline male & $154(75.1 \%)$ & $223(54.4 \%)$ & & \\
\hline female & $51(24.9 \%)$ & $187(45.6 \%)$ & & \\
\hline Birth weight & & & 13.655 & $<0.001$ \\
\hline SGA & $44(21.5 \%)$ & $42(10.5 \%)$ & & \\
\hline AGA & $161(78.5 \%)$ & $368(89.5 \%)$ & & \\
\hline PROM & & & 12.276 & $<0.001$ \\
\hline with & $62(30.2 \%)$ & $63(15.4 \%)$ & & \\
\hline without & $155(69.8 \%)$ & $347(84.6 \%)$ & & \\
\hline Cord around neck with compression & & & 2.769 & 0.096 \\
\hline with & $29(14.1 \%)$ & $79(19.6 \%)$ & & \\
\hline without & $176(85.9 \%)$ & $331(80.4 \%)$ & & \\
\hline Meconium staining of amniotic fluid & & & 5.219 & 0.022 \\
\hline with & $28(13.7 \%)$ & $33(7.9 \%)$ & & \\
\hline without & $177(86.3 \%)$ & $377(92.1 \%)$ & & \\
\hline Oligohydramnion & & & 6.269 & 0.012 \\
\hline with & $31(15.1 \%)$ & $25(6.0 \%)$ & & \\
\hline without & $174(84.9 \%)$ & $385(94.0 \%)$ & & \\
\hline Gestational age & & & 22.942 & $<0.001$ \\
\hline$\leq 38 \mathrm{wks}$ & $65(31.7 \%)$ & $62(15.1 \%)$ & & \\
\hline$>38 \mathrm{wks}$ & $140(68.3)$ & $348(84.9 \%)$ & & \\
\hline Placental abruption & $115(64 \%)$ & $323(78.7 \%)$ & 0.227 & 0.634 \\
\hline with & $2(1.0 \%)$ & $6(1.4 \%)$ & & \\
\hline without & $203(99.0 \%)$ & $404(98.6 \%)$ & & \\
\hline Severe fetal distress & & & 7.216 & 0.007 \\
\hline with & $45(22 \%)$ & $44(10.5 \%)$ & & \\
\hline without & $160(78 \%) \S$ & $366(89.5 \%)$ & & \\
\hline Severe birth asphyxia & & & 38.120 & $<0.001$ \\
\hline with & $33(14.8 \%)$ & $11(2.6 \%)$ & & \\
\hline without & $172(84.7 \%)$ & $399(97.4 \%)$ & & \\
\hline Materno-fetal infection & & & 29.223 & $<0.001$ \\
\hline with & $68(33.2 \%)$ & $29(7.1 \%)$ & & \\
\hline without & $137(66.8 \%)$ & $381(92.9)$ & & \\
\hline
\end{tabular}

SCS: selective cesarean section; PROM: premature rupture of membranes; SGA: small for gestational age; AGA: appropriate for gestational age

subcostal retractions, cyanosis, and reduced or absent breath sounds, and severe dyspnea requiring continuous positive pressure ventilatory support for at least 72 hours; (5) typical chest X-ray findings, such as hypoexpansion, diffuse, fine granular densities, air bronchogram sign, ground-glass opacity, blurred cardiac borders, or white lungs; and (6) arterial blood gas analysis showing hypoxia, hypercapnia, and an oxygen tension/fraction of inspired oxygen ratio $\left(\mathrm{PaO}_{2} / \mathrm{FiO}_{2}\right)$ $\leq 26.7 \mathrm{kPa}$. A total of 410 full-term neonates with jaundice who were admitted to the same hospital over the same period were included as controls. Those with jaundice caused by infectious diseases, such as septicemia and bacterial pneumonia, were excluded.

Additionally, the other diagnostic criteria used in this study were as following: severe birth asphyxia was diagnosed according to the Expert's consensus on the criteria for the diagnosis and grading of 
TABLE 2. Logistic analysis of multi-factor for full-term neonatal RDS

\begin{tabular}{lcccccc}
\hline Risk Factors & B-value & SE & Wald $^{2}$ & p value & OR & $95 \%$ CI \\
\hline SCS & 2.168 & 0.262 & 68.673 & 0.000 & 8.737 & $5.232-14.588$ \\
Birth Asphyxia & 1.944 & 0.433 & 20.147 & 0.000 & 6.988 & $2.990-16.333$ \\
Small GA & 1.111 & 0.273 & 20.111 & 0.000 & 6.222 & $2.001-8.993$ \\
MFI & 1.321 & 0.281 & 29.333 & 0.000 & 5.337 & $1.999-80232$ \\
PROM & 1.218 & 0.271 & 20.133 & 0.000 & 3.380 & $1.986-5.754$ \\
Male & 0.971 & 0.218 & 19.761 & 0.000 & 2.641 \\
PAGTD & 0.882 & 0.381 & 19.761 & 0.000 & 2.415 \\
LBW & 0.843 & 0.285 & 8.748 & 0.003 & $1.721-4.053$ \\
\hline
\end{tabular}

SCS: selective cesarean section; Small GA: gestational age $\leq 38$ weeks; MFI: maternal-fetal infection; PROM: premature rupture of membranes; PAGTD: pregnancy abnormal glucose tolerance or diabetes; LBW: low birth weight

TABLE 3. The influence of some risk factors on outcomes of RDS infants

\begin{tabular}{|c|c|c|c|c|c|c|}
\hline & \multicolumn{2}{|c|}{ PROM (n) } & \multicolumn{2}{|c|}{ Severe asphyxia (n) } & \multicolumn{2}{|c|}{ Maternal-fetal infection (n) } \\
\hline & with (62) & without (155) & with (33) & without (172) & with (68) & without (137) \\
\hline Deaths(\%) & $5(8.06)$ & $3(1.94)$ & $4(12.12)$ & $4(2.32)$ & $6(8.82)$ & $2(1.46)$ \\
\hline LOHS (days) & $21.99 \pm 1.87$ & $17.11 \pm 2.11$ & $23.07 \pm 2.01$ & $16.78 \pm 2.23$ & $22.77 \pm 1.81$ & $17.11 \pm 2.57$ \\
\hline$\chi^{2 / t}$ & \multicolumn{2}{|c|}{$4.685 / 1.91$} & \multicolumn{2}{|c|}{$7.084 / 2.21$} & \multicolumn{2}{|c|}{$4.764 / 1.99$} \\
\hline $\mathrm{p}$ & \multicolumn{2}{|c|}{$0.03 / 0.041$} & \multicolumn{2}{|c|}{$0.008 / 0.019$} & \multicolumn{2}{|c|}{$0.029 / 0.021$} \\
\hline
\end{tabular}

LOHS: length of hospital stay; RDS: respiratory distress syndrome

neonatal asphyxia in China, i.e. Apgar Score $\leq 7$ at 1 to 5 minutes after birth with umbilical arterial $\mathrm{pH}<7.15$, and with at least one hypoxic-ischemic organ injury (such as hypoxic-ischemic encephalopathy, etc.). These guidelines were established by the Neonatal Professional Committee of the Chinese Medical Doctor Association (6). Meconium stained amniotic fluid means dark green and foulsmelling amniotic fluid contaminated with meconium (7). Maternalfetal infection means fetal-neonatal infectious diseases such as pneumonia/septicemia caused by intra-amniotic infection (7). Severe fetal distress was diagnosed as a significant abnormality in the fetal heart rate according to the results of fetal heart rate monitoring (7).

\section{Statistical analysis}

Data analysis was conducted using SPSS 16.0 for Windows (Inc., Chicago, IL, USA). The $\chi^{2}$ tests or Fisher's exact text were used for One-way risk factor analysis and the comparison of mortality rate between two groups, Student's $t$ test was used for the comparison of the length of hospital stay between the two groups, and the effects of multiple factors on term neonatal RDS were analyzed using logistic regression analysis. A p $<0.05$ was considered to be statistically significant.

\section{RESULTS}

One-way risk factor analysis of RDS in term neonates

Table 1 shows that selective cesarean section $\left(x^{2}=14.508\right.$, $\mathrm{p}<0.001)$, male sex $\left(\mathrm{x}^{2}=24.860, \mathrm{p}<0.001\right)$, low birth weight $\left(x^{2}=13.655, p<0.001\right)$, oligohydramnios $\left(x^{2}=6.269, p=0.012\right)$, meconium staining of amniotic fluid $\left(\mathrm{x}^{2}=5.219, \mathrm{p}=0.022\right)$, severe fetal distress and birth asphyxia $\left(\mathrm{x}^{2}=38.120, \mathrm{p}<0.001\right)$, small for gestational age $(\leq 38$ weeks $)\left(x^{2}=5.899, p<0.001\right)$,
PROM $\left(\mathrm{x}^{2}=7.216, \mathrm{p}=0.005\right), \quad$ maternal-fetal infection $\left(x^{2}=29.223, \mathrm{p}<0.001\right)$, and gestational glucose intolerance or diabetes $\left(\mathrm{x}^{2}=5.047, \mathrm{p}=0.025\right)$ were risk factors for RDS in term neonates. The age of pregnancy, cord around the neck with compression, and placental abruption were not significant risk factors for RDS in term neonates.

\section{Logistic regression analysis of multiple factors for term neonatal RDS}

We found that selective cesarean section (odds ratio (OR): 8.737; 95\% confidence interval (CI): 5.232-14.588), severe birth asphyxia (OR: 6.988; 95\% CI: 2.990-16.333), small for gestational age (OR: 6.222; 95\% CI: 2.001-8.993), maternalfetal infection (OR: 5.337; 95\% CI: 1.999-8.233), PROM (OR: 3.380; 95\% CI: 1.986-5.754), male sex (OR: 2.641; 95\% CI: $1.721-4.053)$, gestational glucose intolerance or diabetes (OR: 2.415; 95\% CI: 1.721-4.053), and low birth weight (OR: 2.323; 95\% CI: 1.329-4.060) were the main risk factors of RDS in full-term neonates (Table 2).

\section{Outcomes of RDS patients}

In total, 197 patients showed a full recovery out of 205 RDS cases while eight cases ended in death with an average mortality of $3.90 \%$. The average length of hospital stay in surviving babies was $(19.95 \pm 2.21)$ days. There were no difference between risk factors and mechanical ventilation type $\left(\mathrm{x}^{2}=1.13, \mathrm{p}=0.371\right)$. It can be seen, however, in Table 3 that PROM, severe asphyxia and maternal-fetal infection significantly increased mortality in RDS patients $(\mathrm{p}<0.05)$ and markedly prolonged their length of hospital stay $(\mathrm{p}<0.05)$. 


\section{DISCUSSION}

The results of this study show that selective cesarean section, severe birth asphyxia, PROM, male sex, and gestational glucose intolerance or diabetes are the main risk factors of RDS in full-term neonates. It is well-known that the factors small for gestational age, low birth weight, and gestational glucose intolerance or diabetes play a role in the mechanisms of RDS. Therefore, we focused on the other high-risk factors.

Selective cesarean section is one of the most important risk factors of RDS in term neonates. The reasons for this are as follows (8-14). 1- There is less activity of amiloride-sensitive sodium channels in alveolar epithelial cells following cesarean section, leading to reduced fluid clearance. 2- Leading to relative premature birth. When a cesarean section is performed early, the incidence of RDS increases in full-term neonates. In our study, $31.7 \%$ of infants were in the RDS group at gestational age $\leq 38$ weeks, while it was only $15.1 \%$ in non-RDS neonates.

Severe birth asphyxia and maternal-fetal infection are the important causes of term neonatal RDS (5). This may be because of the following two reasons: 1- acute lung injury caused by severe birth asphyxia or maternal-fetal infection decreases the synthesis and secretion of PS; and 2- hypoxia or maternalfetal infection inhibits the activity of PS and even leads to its inactivation. Moreover, severe asphyxia and maternal-fetal infection can increase mortality and extend the length of hospital stay of RDS patients; thus, it is important for us to pay attention to the management of these patients.

This study is the first to show that male sex is a risk factor for term neonatal RDS. The relative risk of RDS is 2.641 times higher for males than females. It is believed that the female fetal lung produces surfactant earlier in gestation than the male fetal lung. The reasons for this finding may be as follows (15-18). 1- Androgens delay lung fibroblast secretion of fibroblast-pneumocyte factor, which can delay the development of alveolar type II cells and reduce the release of PS. 2- Androgens slow fetal lung development by adjusting the signaling pathways of epidermal growth factor and transforming growth factor-beta. 3- Estrogen promotes the synthesis of PS, including phospholipids, lecithin, and surfactant proteins A and B. 4- Estrogen also improves fetal lung development by increasing the number of alveolar type II cells and by increasing the formation of lamellated bodies.

The results of this study demonstrate that PROM is also an important risk factor for term neonatal RDS. We hypothesize that there are several reasons why this may be the case (10, 19). 1- PROM leads to maternal-fetal infection; this occurs in nearly $1 / 3$ of patients with PROM (20). Intrauterine infection and chorioamnionitis caused by PROM can result in direct injury to the fetal lungs and alveolar type II cells, decreasing the synthesis or release of surfactant. 2- Fetal-neonatal lung inflammation increases the permeability of the alveolar-capil- lary membrane to both fluid and solutes. This results in plasma proteins entering the alveolar hypophase, which further inhibits the function of surfactant. 3- PROM leads to relatively premature birth. The OR of a neonate born at $\leq 38$ weeks gestation suffering RDS versus a neonate born at $>38$ weeks is 6.222 (95\% CI: 2.001-8.993). Therefore, relative premature birth is one of the important reasons why RDS is related to PROM. Similar to birth asphyxia and maternal-fetal infection, PROM can also increase mortality and extend the length of hospital stay of RDS patients; thus, it is also important to pay attention to the management of RDS patients with PROM.

In conclusion, the results of the present investigation show that selective cesarean section, severe birth asphyxia, PROM, male sex, gestational glucose intolerance or diabetes, low birth weight, small for gestational age and maternal-fetal infection are high-risk factors for developing RDS in term neonates. These findings have important clinical implications for the diagnosis and treatment of term neonatal RDS.

Ethics Committee Approval: Ethics committee approval was received for this study from the ethics committee of the Beijing Military General Hospital.

Informed Consent: Written informed consent was obtained from patients' parents who participated in this study.

Peer-review: Externally peer-reviewed.

Author contributions: Concept - L.J.; Design - L.J.; Supervision - L.J.; Resource - Y.N.; Materials - L.J., Y.N., L.Y.; Data Collection\&/or Processing - Y.N., L.Y.; Analysis\&/or Interpretation - L.J., Y.N.; Literature Search - Y.N., L.Y.; Writing - L.J.; Critical Reviews - L.J.

Acknowledgements: We appreciate Miss Guang-Pei Gao, who has polished this paper for us carefully.

Conflict of Interest: No conflict of interest was declared by the authors.

Financial Disclosure: This work was supported by China Postdoctoral Science Foundation (20080431405\&200801041) and CJP-Kelisu Research Funding (cjp2011005).

\section{REFERENCES}

1. Koivisto M, Marttila R, Kurkinen-Raty M, Saarela T, Pokela ML, Jouppila $\mathrm{P}$, et al. Changing incidence and outcome of infants with respiratory distress syndrome in the 1990's: a population-based survey. Acta Paediatr 2004;93:177-84. [CrossRef]

2. Faix RG, Viscardi RM, DiPietro MA, Nicks JJ. Adult respiratory distress syndrome in full-term newborns. Pediatirics 1989;83:971-6.

3. Ayachi A, Rigourd V, Kieffer F, Dommergues MA, Voyer M, Magny JF. Hyaline membrane disease in full-term neonates. Arch Pediatr 2005;12:156-9. [CrossRef]

4. Bouziri A, Ben Slima S, Hamdi A, Menif K, Belhadj S, Khaldi A, et al. Acute respiratory distress syndrome in infants at term and near term about 23 cases. Tunis Med 2007;85:874-9.

5. Liu J, Shi Y, Dong JY, Zheng T, Li JY, Lu LL, et al. Clinical characteristics, diagnosis and management of respiratory distress syndrome in full-term neonates. Chin Med J (Engl) 2010;123:2640-4.

6. Naonatal Professional Committee of Chinese Medical Doctor Association. Expert's consensus on the criteria for the diagnosis and 
grading of neonatal asphyxia in China. Zhongguo Dangdai Er Ke Za Zhi 2013;15:1

7. Martin RJ, Fanaroff AA, Walsh MC. Fanaroff \& Martin's NeonatalPerinatal Medicine: Diseases of the Fetus and Infant. Elsevier Mosby Inc.,9th Edition, Louis, USA,2011: 181-187;402-410.

8. Greenough A. Acute respiratory distress syndrome. In: Greenough A, Milner AD, eds. Neonatal Respiratory Disorders. $2^{\text {nd }}$ edition, Arnold: London;2005:396-398.

9. Greenough A, Roberton NRC. Acute respiratory disease in the newborn, In:Renme JM, Roberton NRC, eds. Textbook of Neonatology. $3^{\text {rd }}$ edition, Churchill Livingltone: London;1999:481-483.

10. Jain L, Eaton DC. Physiology of fetal lung fluid clearance and the effect of labor. Semin Perinatol 2006;30:34-43. [CrossRef]

11. Hansen AK, Wisborg K, Uldbjerg N, Henriksen TB. Risk of respiratory morbidity in term infants delivered by elective caesarean section: cohort study. BMJ 2008;336:85-7. [CrossRef]

12. Tita ATN, Landon MB, Spong CY, Lai Y, Leveno KJ, Varner MW. Timing of elective repeat cesarean delivery at term and neonatal outcomes. N Engl J Med 2009;360:111-20. [CrossRef]

13. Farchi S, Di Lallo D, Polo A, Franco F, Lucchini R, De Curtis M. Timing of repeat elective caesarean delivery and neonatal respiratory outcomes. Arch Dis Child Fetal Neonatal Ed 2010; 95:F78. [CrossRef]
14. Robinson CJ, Villers MS, Johnson DD, Simpson KN. Timing of elective repeat cesarean delivery at term and neonatal outcomes: a cost analysis. Am J Obstet Gynecol 2010;202:632.e1-e6.

15. Nielsen HC, Torday JS. Sex Differences in avian embryo pulmonary surfactant production:evidence for sex chromosome involvement. Endocrinology 1985;117:31-7. [CrossRef]

16. Seaborn T, Simard M, Provost PR. Sex hormone metabolism in lung development and maturation. Trends Endocrinol Metab 2010;21:729-38. [CrossRef]

17. Nielsen HC. Androgen receptors influence the production of pulmonary surfactant in the testicular feminization mouse fetus. $J$ Clin Invest 1985;76:177-81. [CrossRef]

18. Bresson E, Seaboorn T, Côté M, Cormier G, Provost PR, Piedboeuf B, et al. Gene expression profile of androgen modulated genes in the murine fetal developing lung. Reprod Biol Endocrinol 2010;8:2. [CrossRef]

19. Yang LC, Taylor DR, Kaufman HH, Hume R, Calhoun B. Maternal and fetal outcomes of spontaneous preterm premature rupture of membranes. JAOA 2004; 104:537-42.

20. Liu J, Feng ZC, Wu J. The Incidence rate of premature rupture of membranes and its influence on fetal-neonatal health: a report from mainland China. J Trop Pediatr 2010;56:36-42. [CrossRef] 